\title{
Análise sobre a formação agronômica em interface com a agroecologia de acadêmicos do curso de Agronomia, no IFMT - Campus Campo Novo do Parecis
}

\section{Analysis on the agronomic training in Agroecology interface of course scholars of Agronomy, in IFMT - Campus Campo Novo do Parecis}

\author{
Arnaldo Gonçalves de Campos $^{1}$; Leandro Carbo ${ }^{2 *}$; Jorge Luiz da Silva ${ }^{3}$; Geison Jader Mello ${ }^{4}$; Ronaldo Eustáquio Feitoza \\ Senra
}

\begin{abstract}
Resumo: O presente trabalho teve como objetivo analisar o processo de formação de acadêmicos do curso de Agronomia do Instituto Federal de Educação, Ciência e Tecnologia do Mato Grosso, Campus Campo Novo do Parecis, sobre o tema Agroecologia, buscando diagnosticar perfil, concepções e identificar as percepções do tema para a vida profissional. Quanto à forma de abordagem houve uma mescla entre os métodos quantitativos e qualitativos. Os instrumentos utilizados na coleta de dados foram a análise documental (plano de curso e matriz curricular) e questionário. Da conclusão, destacam-se a ausência de uma conceituação teórica bem fundamentada em relação à abrangência da proposta agroecológica, e, boa percepção sobre a relevância da temática, onde os acadêmicos manifestaram de forma geral grande preocupação com a questão da sustentabilidade para o futuro da agricultura. Percebeu-se ainda, que o plano de curso da instituição é politicamente bem discutido, porém, na estrutura curricular de sua matriz, não fica contemplado efetivamente todos os critérios necessários à formação do agrônomo no quesito sustentabilidade.
\end{abstract}

Palavras-chaves: Educação agrícola superior, bacharelado em agronomia, matriz curricular.

Abstract: This study aimed to analyze the process of formation of students of Agronomy at the Federal Institute of Education, Science and Technology of Mato Grosso, Campus Campo Novo do Parecis on the theme Agroecology, seeking to diagnose profile, identify the perceptions and conceptions theme for professional life. As for how to approach was a mix between quantitative and qualitative methods. The instruments used in data collection were document analysis (course plan and syllabus) and questionnaire. Conclusion, we highlight the absence of a well-grounded theoretical conceptualization regarding the scope of the agroecological proposal, and good insight into the relevance of the theme, where academics have expressed great concern about the general issue of sustainability for the future of agriculture. It was noticed also that the course plan of the institution is politically well discussed, however, the curricular structure of your matrix is not effectively covered all necessary to the formation of an agricultural sustainability criteria in the category.

Key words: Agricultural higher education, bachelor of agronomy, curricular matrix.

\footnotetext{
*Autor para correspondência

Recebido para publicação em 10/09/2015; aprovado em 20/12/2015

${ }^{1}$ Mestre em Educação Agrícola, Instituto Federal de Educação, Ciência e Tecnologia de Mato Grosso (IFMT) - Campus São Vicente - Núcleo Avançado de Jaciara, Jaciara - MT; (65) 9925-4343, arnaldo.gonçalves@ svc.ifmt.edu.br.

${ }^{2}$ Doutor em Química, Instituto Federal de Educação, Ciência e Tecnologia de Mato Grosso (IFMT) - Campus São Vicente - Núcleo Avançado de Jaciara, leandro.carbo@svc.ifmt.edu.br.

${ }^{3}$ Mestre em Ciência Animal, Instituto Federal de Educação, Ciência e Tecnologia de Mato Grosso (IFMT) - Campus São Vicente - Núcleo Avançado de Jaciara, jorge.silvas@svc.ifmt.edu.br.

${ }^{4}$ Doutor em Física Ambiental, Instituto Federal de Educação, Ciência e Tecnologia de Mato Grosso (IFMT) - Campus São Vicente - Núcleo Avançado de Jaciara, geison.mello@svc.ifmt.edu.br.

${ }^{5}$ Doutor em Educação, Instituto Federal de Educação, Ciência e Tecnologia de Mato Grosso (IFMT) - Campus São Vicente - Núcleo Avançado de Jaciara, ronaldo.senra@svc.ifmt.edu.br.
} 


\section{INTRODUÇÃO}

A agricultura convencional praticada atualmente está construída em torno de dois objetivos que relaciona a maximização de produção e do lucro, considerando-se assim, muito restritamente as dimensões sociais, éticas, culturais, bem como as questões ambientais da atividade (GLIESSEMAN, 2009).

Segundo Jesus (1996), a maximização de lucros nem sempre foi compatível com a busca de soluções para as questões sociais e culturais e com a reprodutibilidade ecológica do sistema agrícola em longo prazo.

$O$ discurso sobre a necessidade de aumentar a produtividade para acabar com a fome, serviu para mascarar o objetivo implícito da maximização do lucro, pois seria necessário pesquisar culturas alimentares e não as de exportação (BONILLA, 2001). Ainda segundo o autor, outro aspecto importante, seria repensar sobre onde plantar e como distribuir os alimentos, o que às vezes, não tem estado na pauta da pesquisa convencional. Nesse mesmo contexto, seria a inclusão da dimensão ética na pesquisa, situação em que permitiria separar os objetivos verdadeiros dos declarados da própria pesquisa.

Há de se entender que o trajeto regular para o processo de transição na agricultura perpasse pela formação do agrônomo. Sobre esse aspecto, Silveira Filho (2011) argumenta que existe um vínculo histórico de forte relação entre a formação do agrônomo e o processo de transformação da agricultura. Segundo o autor, não dá para tratar a formação do agrônomo e as mudanças pelas quais a mesma tem passado sem deixar de associá-las às transformações da agricultura. Evidencia-se, portanto, que a formação deste profissional não deve ser alicerçada no velho discurso de "produzir alimentos para acabar com a fome no mundo", mas sim que seja comprometida especialmente com a equidade social e com o respeito ao meio ambiente.

O ensino da Agronomia, enquanto formação escolar, tem organizado os conhecimentos e saberes através de currículos que expressam interesses de setores dominantes (CAVALLET, 1999). O autor menciona ainda, que o ensino da Agronomia, apesar de ter contribuído com a formação de profissionais e consequentemente com o avanço da produção agrícola, por outro lado, ao ignorar os conflitos e contradições econômicas, sociais, ecológicas e culturais do meio agrário, favoreceu determinados grupos em detrimento de outros grupos.

Mudanças na formação de profissionais das ciências agrárias tornam-se uma tarefa inadiável e imprescindível, no contexto das mudanças e expectativas, caracterizadas pelo novo milênio (SOARES; BRAGA, 1997). Segundo estes autores, inúmeras dificuldades deverão ser enfrentadas e, se não houver mudanças, os cursos de graduação desta área formarão profissionais preparados para atuar na sociedade do passado, e não na contemporânea e futura.

Os profissionais do futuro deverão estar preparados para ocupar espaços de relevância na sociedade, ter capacidade para lidar com situações que vão além do conhecimento técnico, preparados para se posicionar tanto nas discussões como nas propostas para soluções de problemas ambientais da sociedade (SOUZA, 2006).
Sobre esse aspecto, a Lei de Diretrizes e Bases da Educação (LDB) - Lei No 9.394/96, no seu capítulo III, Art. 39, que trata da educação profisssional, traz que: "A educação profissional, integrada às diferentes formas de educação, ao trabalho, à ciência e à tecnologia conduz ao permanente desenvolvimento de aptidões para a vida produtiva" (BRASIL, 1997).

Nesse contexto, a agroecologia vem surgindo com a promessa de se oferecer bases científicas para se estabelecer o desenvolvimento rural sustentável. Para Campos (2013), na ótica dessa ciência, a agricultura é vista de forma sistêmica, ou seja, a formação do agrônomo deve ser tratada numa perspectiva didática integralizadora do conhecimento. Assim, apresenta uma possibilidade de se redesenhar novos caminhos para a agricultura do presente e do futuro. Segundo Gliesseman (2009), a agroecologia proporciona o conhecimento e a metodologia necessários para desenvolver uma agricultura que é ambientalmente consistente, altamente produtiva e economicamente viável.

O objetivo do presente trabalho foi diagnosticar o perfil e as concepções de acadêmicos do curso de Agronomia do Instituto Federal de Educação, Ciência e Tecnologia do Mato Grosso, Campus Campo Novo do Parecis, sobre o tema agroecologia, buscando identificar as percepções do tema para a vida profissional.

\section{MATERIAL E MÉTODOS}

A presente pesquisa se classifica como investigação do tipo exploratória, na área de conhecimento de "Ciências Humanas" (GIL, 2010). Considerando-se a natureza dos dados em relação ao procedimento de análise realizada, adotou-se a interação entre dados "Quantitativos e Qualitativos”. Os métodos qualitativos e os quantitativos podem ser associados de diversas maneiras no planejamento de um estudo (FLICK, 2009).

Em relação à estratégia de pesquisa, foi adotado o "Estudo de Caso", pois segundo Yin (2010) tem sido recomendado por diversos autores para a elucidação de casos semelhantes.

Os dados da pesquisa foram coletados entre os meses de julho e dezembro de 2011, com 24 acadêmicos do sexto semestre do curso de agronomia do IFMT, Campus - Campo Novo do Parecis. Foram utilizados os seguintes instrumentos de coleta de dados: análise documental (plano de curso e matriz curricular) e questionário.

O início das atividades ocorreu através de uma reunião realizada no Campus, com os acadêmicos integrantes da turma. Como primeira etapa da pesquisa, foi apresentada aos estudantes: a problemática de estudo, os objetivos e a metodologia do trabalho. Em seguida, foi aplicado o questionário a todos os acadêmicos da turma. O questionário constituiu-se em um dos instrumentos de amostragem aplicado a fim de diagnosticar a origem e perfil vocacional dos estudantes do curso de agronomia, bem como para avaliar o nível conceitual desses acadêmicos, sobre o tema agroecologia.

Quanto à forma das perguntas que compuseram o questionário, foram adotadas as três categorias gerais: questões abertas, fechadas e de múltipla escolha, conforme 
definição apresentada por Marconi e Lakatos (2010). Para Oliveira (2011), o questionário fornece subsídios reais do universo ou da amostra pesquisada, por isso, é considerado um importante instrumento de pesquisa.

Posteriormente, procedeu-se a análise documental que foi uma importante fonte de coleta de dados utilizada nessa pesquisa, auxiliando na compreensão sobre a formação do agrônomo na instituição. Para alcançar essa finalidade, foram examinados os seguintes documentos institucionais: O Plano e a Matriz Curricular do curso de agronomia do campus. De acordo com Gil (2010), o uso de consulta a fontes documentais é imprescindível em qualquer estudo de caso. $\mathrm{O}$ autor ressalta ainda, que essas informações podem auxiliar na elaboração das pautas para entrevistas e dos planos de observação.

Antes da análise e interpretação, os dados obtidos na pesquisa passaram pelas etapas de seleção, codificação e tabulação, em conformidade com as recomendações sugeridas por Marconi e Lakatos (2010).

\section{RESULTADOS}

\section{O perfil profissional desejado para o egresso em agronomia}

O tema "perfil profissional", tratado à luz do Plano de Curso (PC), do curso de Agronomia da instituição, é politicamente bem discutido em termos de expectativas para o egresso, porém, a estrutura curricular de sua Matriz, não contempla efetivamente todos os aspectos mencionados no mesmo. No que concerne "à formação do agrônomo relacionada à sustentabilidade", questão que é investigada nessa pesquisa, percebe-se que poderia haver a inclusão de diversas outras disciplinas voltadas para busca do equilíbrio ecológico nos agroecossistemas. Além disso, a relevância social da agricultura poderia ter mais ênfase no currículo formativo do curso.

Enquanto instituição de ensino agrícola superior, o IFMT, caminha em busca pela consolidação na qualidade da formação ofertada aos seus estudantes.

Nos últimos anos a demanda por profissionais da agronomia tem sido crescente no Estado de Mato Grosso, entretanto, essa procura tem tido um foco essencialmente em profissionais tecnicista, voltado para a transferência de tecnologia. Esse aspecto merece uma atenção por parte das instituições de ensino agrário, de forma que não incorrer no erro em atender fielmente às demandas impostas pelo mercado de trabalho, mas sendo comprometidas em promover uma formação para a efetiva emancipação intelectual do indivíduo, contribuindo para o desenvolvimento sustentável.

A Influência de uma instituição de ensino agrícola não deve ser restrita apenas na velocidade do desenvolvimento local ou regional, pela qualificação da "mão de obra" que produz, mas deve fazer parte dos rumos e do modelo de desenvolvimento da sociedade.

\section{As disciplinas contempladas na Matriz Curricular}

O plano do curso de agronomia ofertado no IFMT campus Campo Novo do Parecis, possui um perfil formativo tecnicista de base essencialmente convencional. No rol de disciplinas obrigatórias elencadas na matriz curricular, não há nenhuma disciplina voltada para área de ecologia, agroecologia ou qualquer outra que venha propiciar ao aluno o acesso garantido a conhecimentos que possam prepará-lo para o exercício profissional alicerçado no princípio da sustentabilidade (BRASIL, 2008).

Outro aspecto importante é a ausência de disciplinas voltadas para a questão da ética profissional/social, de forma a não assegurar que, uma vez formado, o indivíduo tenha uma concepção clara das relações sociais envolvidas na atividade agrícola ou na prática profissional, e tampouco a consciência legítima de limites entre a produção e a conservação. Qualquer atividade que aconteça durante o desenvolvimento do curso, baseada no princípio da sustentabilidade, ocorre por iniciativa de algum professor, pois esse aspecto, como já foi dito, não é assegurado no plano de curso.

Sobre as disciplinas que devem integrar ao currículo dos cursos da área agrária, Maia et al., (2006) enfatiza que o maior problema consiste em oferecer disciplinas com conteúdos úteis e importantes para a formação de profissionais, que tenham habilidades o suficiente para que se possa atender aos diversos nichos potenciais, tais como: às ambições pessoais, às organizações, empresas e instituições que irão empregá-los (demanda ocupacional), bem como aos agricultores e suas famílias (demanda social). Os mesmos autores ressaltam ainda, que para isto ocorra tornam-se necessárias a avaliação e a atualização permanente das disciplinas e seus conteúdos e, obviamente, a identificação dos problemas de importância agrícola.

A formação de um novo profissional da Agronomia é um requisito indispensável para uma agricultura sustentável (SARANDÓN, 2002). Segundo o mesmo autor, o perfil desse profissional deve incorporar uma abordagem holística e sistêmica, de forma que o mesmo tenha atitude ética, adequado espírito crítico e sólidos conhecimentos sobre o condicionamento dos agroecossistemas aos aspectos econômicos e socioculturais. Neste sentido, Morin (2003, p.65), “A educação deve contribuir para a autoformação da pessoa (ensinar a assumir a condição humana, ensinar a viver) e ensinar como se tornar cidadão". Para esse autor, um cidadão é definido em uma democracia, por sua solidariedade e responsabilidade em relação a sua pátria.

Ao contrário das formas compartimentadas de ver e estudar a realidade, das ciências convencionais, baseadas no paradigma cartesiano, a Agroecologia integra e articula conhecimentos de diferentes ciências (CAPORAL; COSTABEBER, PAULUS, 2006). Deste modo, a agroecologia como matriz disciplinar vem aportando as bases para um novo paradigma científico, que, ao contrário do convencional a ciência, procura ser integradora, rompendo com o isolacionismo das ciências e das disciplinas gerado pelo paradigma cartesiano.

Dessa forma, entende-se, que é um momento propício para uma rediscussão do atual currículo do curso, de forma a incorporar algumas disciplinas de base sustentável de modo que se possa assegurar a discussão dos aspectos conservacionistas, da ética social e do equilíbrio econômico.

\section{Concepções sobre o termo Agroecologia}

Quando perguntados se já haviam ouvido falar sobre agroecologia, todos os estudantes amostrados mencionaram ter alguma noção sobre o assunto, demonstrando, portanto, 
que não é um termo estranho ou desconhecido, e que de todos já tinham algum conceito preestabelecido.

Apesar de se verificar que todos os acadêmicos da turma já tinham alguma noção sobre o termo agroecologia, ao analisar suas concepções, foi observado que não há uma conceituação teórica bem fundamentada sobre a abrangência da proposta agroecológica. $\mathrm{Na}$ maioria das respostas dadas aos questionamentos realizados junto aos estudantes, observou-se ainda, que foi dada maior ênfase à dimensão ecológica da agroecologia, entretanto, a maioria dos autores discute essa ciência, abordando os seus aspectos ecológicos, econômicos e sociais, culturais, políticos e éticos.

Outro fator bastante relevante levantado na pesquisa, foi o fato de que, apesar de se constatar que esses acadêmicos não possuíam uma concepção bem formulada sobre a abrangência da agroecologia, enquanto ciência, todos os indivíduos envolvidos na pesquisa apresentaram preocupação sobre o assunto, ao manifestarem a questão da sustentabilidade na agricultura como prioridade.

$\mathrm{O}$ aumento da produtividade aliado à sustentabilidade foi apontado pelos acadêmicos como o principal e maior desafio a ser enfrentado pelo setor agrícola no futuro, além disso, buscar conhecimentos para permitir que isso aconteça, ficou evidenciado, como o principal papel do agrônomo nesse contexto. A construção coletiva do conhecimento e redesenho agrícola, foram destacados como os possíveis caminhos para uma agricultura de base agroecológica.

Nesse mesmo questionamento foram verificados também, quais teriam sido os veículos de comunicação pelos quais a Agroecologia foi apresentada a esses estudantes pesquisados. Os resultados obtidos apontaram os veículos de comunicação mais eficientes, bem como suas respectivas ordens de escolha, distribuídos da seguinte forma: $24 \%$ conheceram a Agroecologia através de aula; $21 \%$ pela televisão; $17 \%$ pela internet; $17 \%$ por meio de palestra; $12 \%$ por revista e os $9 \%$ restantes ficaram entre rádio e jornal.

Os valores apresentados a seguir demonstram o potencial do ambiente escolar enquanto veículo difusor do conhecimento, pois apesar da agroecologia não figurar entre as disciplinas oferecidas na matriz curricular do curso, percebe-se, que mesmo assim, a sala de aula se destacou como sendo o veículo de maior eficácia na apresentação do assunto aos estudantes. Isso demonstra ainda, que embora o estudante de graduação tenha um nível de maturidade suficientemente preparado para realizar suas próprias descobertas, o veículo de maior alcance ocorreu via escola, justificando, portanto, a necessidade de se inserir assuntos de maior relevância no acervo curricular de cada curso.

Quanto à concepção dos acadêmicos sobre a definição conceitual do termo agroecologia, $42 \%$ dos estudantes acreditam que o termo se refere a "um estilo de agricultura"; $33 \%$ acreditam que seja uma "técnica de produção"; $21 \%$ conceituaram-na como "ciência" e 4\%relataram que se refere a uma maneira de se produzir de forma sustentável.

Nesse sentido, Bonilla (2001), relata que são comuns as interpretações que vinculam a Agroecologia a alguns conceitos equivocados, tais como: "uma vida mais saudável"; "uma agricultura socialmente justa"; "uma agricultura que não exclui ninguém"; entre outros. Sendo assim, segundo o mesmo autor, o uso do termo agroecologia tem trazido a ideia e a expectativa de uma nova agricultura capaz de fazer bem ao homem e ao meio ambiente.
De acordo com a situação exposta acima, e dos resultados alcançados nessa pesquisa, verificou-se, que ainda existe confusão quanto à aplicação conceitual do termo agroecologia, gerando interpretações bastante distintas, e, segundo Caporal; Costabeber e Paulus (2006), em muitos casos, prejudicam o entendimento da agroecologia enquanto "ciência que estabelece as bases para a construção de estilos de agriculturas sustentáveis e de estratégias de desenvolvimento rural sustentável".

Desse modo, constatou-se que já existe certa politização sobre a questão da agroecologia entre os acadêmicos amostrados, porém os resultados da pesquisa demonstraram que o maior percentual de respostas se relacionam a uma espécie de pseudopolitização, quando apenas $21 \%$ dos acadêmicos apontaram a Agroecologia como ciência.

Sobre os meios de comunicação que veicularam a maioria das informações sobre essa temática, são bem variados, e a maioria deles não oportuniza a discussão e o esclarecimento de possíveis dúvidas, gerando assim, interpretações distorcidas e equivocadas.

Quanto ao enfoque agroecológico demanda a construção de uma nova postura teórico/metodológica por parte dos docentes na concepção da matriz curricular dos cursos, de forma que se possa formar profissionais que sejam agentes de desenvolvimento local sustentável, diferentemente da formação técnica vigente (SILVA, 2008).

Foi perguntado aos acadêmicos se na condição de futuros profissionais da área, adotariam alguma prática agroecológica. Os estudantes foram unânimes nas respostas, ao afirmar positivamente quanto à adoção de alguma prática dessa natureza. Como justificativa eles afirmaram que adotariam a prática agroecológica pelos seguintes motivos: a) produzir de forma sustentável, 41\%: "Porque temos que atentar para o futuro, adotando alguma prática agroecológica estaremos pensando nas gerações futuras e utilizando nossos recursos de forma sustentável"; b) conservação ambiental, com 33\% das escolhas: "Pelo fato de achar que a agricultura hoje é realizada de forma agressiva ao meio ambiente, principalmente em relação ao solo"; c) qualidade dos alimentos alcançou um total de 11\%: "Para que os alimentos, principalmente in natura, sejam mais saudáveis e livres de agrotóxicos".

Outras situações que podem ser consideradas relevantes, também foram levantadas como justificativa para adoção das práticas agroecológicas, entre as quais, citam-se: a necessidade de certificação dos produtos com $8 \%$ das escolhas e a questão da rentabilidade com $7 \%$.

Sarandón (2002), enfatiza que a agroecologia surge como um novo campo de conhecimentos, que fornece enfoque científico e reúne, sintetiza e aplica os conhecimentos da agronomia, ecologia, sociologia, da etnobotânica e de outras ciências afins. $\mathrm{O}$ autor ressalta ainda, que a agroecologia trata esses aspectos sob uma ótica holística e sistêmica, para o desenho, manejo e avaliação de agroecossistemas sustentáveis.

\section{Conhecimentos e percepções}

Ao serem questionados sobre o conhecimento ou desconhecimento, de alguma prática de base sustentável adotada na agricultura regional, foram verificados os seguintes resultados: $53 \%$ dos acadêmicos afirmaram que 
conheciam e $47 \%$ que desconheciam. Aos estudantes que afirmaram conhecer alguma prática sustentável utilizada na agricultura regional, foi solicitado que as identificassem. Obteve-se então os seguintes resultados: $32 \%$, plantio direto; $20 \%$, adubação orgânica; $16 \%$, controle biológico. Os outros $32 \%$ foram diluídos entre as seguintes opções: integração lavora/pecuária; compostagem; adubação verde e fixação biológica de Nitrogênio (FBN).

Quando questionados a escolher entre algumas alternativas sugeridas sobre os possíveis caminhos para a agricultura do futuro, $55 \%$ dos acadêmicos apontaram a opção "através da construção coletiva do conhecimento e redesenho agrícola para a sustentabilidade"; $21 \%$ escolheram "com o uso da transferência de tecnologia"; 12\% manifestaram favorável à opção "com o uso de pacotes tecnológicos". Ficando os $12 \%$ restantes incluídos na opção outros, foi verificado as seguintes escolhas: 9\%, "priorização da produtividade" e 3\% optaram pela opção "pesquisa em tecnologia industrial".

Esse resultado revelou um aspecto bastante expressivo, onde a maioria dos acadêmicos manifestou estar ciente, que há a necessidade de se buscar outro caminho para a agricultura. Entretanto, há um percentual significativo de estudantes que acreditam que se deve continuar adotando o atual sistema dominante.

A grande preocupação é que, até mesmo para os que acreditam que o rumo da agricultura no futuro deve mudar, na prática ainda são muito tímidas as ações nesse sentido. A grande verdade é que as pessoas que de fato praticam a agricultura têm fechado os olhos, pois está dando certo hoje, e é uma atividade lucrativa. Percebe-se que não há preocupação com aspectos, como: a saúde da população que está sendo ameaçada pelo uso dos agroquímicos; a degradação ambiental; a perda da biodiversidade e tampouco com as gerações futuras.

Neste contexto, o que fica explícito é que as Instituições de Ensino Agrícola Superior -(IEAS), têm deixado a desejar, pois não têm discutido, pesquisado e/ou estimulado seus acadêmicos sobre a possibilidade de se produzir com condições mínimas de recursos, se preocupando apenas em aplicar tecnologia de alto custo que inviabiliza, por exemplo, a agricultura familiar. Dessa forma, as pesquisas para desenvolver tecnologias simples que podem ser extremamente eficazes caminham lentamente, trazendo, cada vez mais, desânimo a pequenos e médios agricultores, e ocasionando consequentemente, o êxodo rural e inflam os subúrbios das grandes cidades, aumentado demasiadamente as desigualdades sociais.

Outro aspecto recorrente, e pouco lembrado, é que, embora o Brasil tenha se destacado mundialmente com um "celeiro de produção de alimentos", a base do nosso sistema agrícola predominante é convencional, sendo, portanto, altamente dependente de insumos externos.

\section{Percepções sobre os novos desafios aos profissionais da agronomia}

Entre os possíveis desafios a serem enfrentados pelo setor agrícola no futuro, os acadêmicos manifestaram suas opiniões da seguinte forma: $43 \%$ apontaram a necessidade de se aliar o aumento da produtividade à sustentabilidade; $14 \%$ atender à crescente demanda por alimentos; $11 \%$ a conservação e preservação ambiental e $8 \%$ os desequilíbrios na natureza. Os $24 \%$ restante, compreendem a opção outros, nesse percentual estão incluídos os seguintes desafios: exigências da legislação; a falta de insumos; responsabilidade social; conscientização das pessoas; mudanças no sistema de manejo produtivo e a falta de profissionais qualificados para essa tarefa.

Nesse sentido, Gliesseman (2009), afirma que a agricultura do futuro deve ser tanto sustentável quanto altamente produtiva para poder alimentar a população humana. Ainda segundo o mesmo autor, a agricultura do futuro requer uma nova abordagem de desenvolvimento, devendo ser reconstruída sobre aspectos de conservação de recursos da agricultura tradicional local, enquanto, ao mesmo tempo se exploram conhecimentos e métodos ecológicos modernos.

Dessa forma, percebe-se que os acadêmicos amostrados, possuem uma concepção bastante relevante, em relação aos desafios para o futuro da atividade agrícola, pois os dados dessapesquisa corroboram com as considerações manifestadas acima por Gliesseman (2009), quando os estudantes explicitaram como maior desafio para o futuro da agricultura, a seguinte resposta: "aliar o aumento da produtividade à sustentabilidade (43\%)".

Sendo assim, entende-se que há um desafio muito maior, que é a inserção do ensino da Agroecologia na pauta de discussões das instituições de ensino agrário, para que possa haver o estímulo ao desenvolvimento ao rural sustentável,por meio de pesquisas dessa natureza, para enfim, chegar até ao domínio do agricultor, sobretudo nas mãos dos agricultores familiares, que muito pouco tem se beneficiado de tecnologias próprias para o seu contexto.

Em sequência ao questionamento anterior sobre "os principais desafios a serem enfrentados pelo setor agrícola no futuro", perguntou-se também aos alunos, qual deveria ser o papel do agrônomo nesse contexto. Entre as diversas respostas, destacou-se com maior frequência, a seguinte: conhecer alternativas para aliar a produtividade à sustentabilidade, com $41 \%$ de representatividade, corroborando, portanto, com a resposta mais expressiva do questionamento anterior. As demais respostas ficaram assim divididas: criar/conhecer e testar novas tecnologias de produção, com 23\%; buscar a produção sustentável, com 13\%; os aspectos dinamismo e informação, com 9\%; e, os outros $14 \%$ ficaram distribuídos entre as seguintes respostas: diagnosticar e solucionar os problemas; produzir alimentos de qualidade e buscar aperfeiçoamento para repassar ao produtor.

De forma geral, quase todas as respostas dadas ao referido questionamento, abordam a questão da sustentabilidade, demonstrando, portanto, que há boa aceitação da discussão entre os acadêmicos, servindo ainda, para mostrar a pertinência do assunto no contexto, necessitando, porém, de um caráter institucional para que se possa alcançar uma dimensão maior no âmbito da comunidade acadêmica do campus.

$\mathrm{Na}$ opinião dos acadêmicos amostrados, para que tenhamos profissionais mais engajados na causa da sustentabilidade agrícola falta: conhecimento sobre a agroecologia; conscientização da sociedade; melhor remuneração à cadeia produtiva envolvida; pesquisa de base sustentável. Os 9\% restante inclui as seguintes respostas: 
falta de preocupação com as gerações futuras; falta de iniciativa governamental que contribua para estimular o desenvolvimento rural sustentável.

Um dos aspectos importantes, que vale ressaltar, é que todas as opiniões apresentadas são aspectos contemplados na proposta da agroecologia.

\section{CONCLUSÕES}

Verificou-se que o projeto formativo do curso de agronomia ofertado atualmente no IFMT - campus Campo Novo do Parecis, não contempla plenamente uma formação para atender aos desafios e demandas atuais e emergentes da agricultura. O currículo do curso é alicerçado essencialmente nos aspectos técnico-produtivos da agricultura convencional, baseado em um modelo que tem predominado historicamente, nãoprevendo suficientemente, as questões ecológicas, sociais e os aspectos qualitativos que envolvem a atividade agrícola.

Evidenciou-se ainda, uma formação alicerçada no tecnicismo mercadológico, onde os saberes agronômicos pertinentes à agroecologia e à agricultura familiar, apresentam-se como lacunas não contempladas na formação destes graduandos. Fica, portanto, evidente que a formação profissional deve estar em processo de constante evolução, de modo que possa atender às novas demandas. Sendo assim, entende-se que a formação do agrônomo seja um fator primordial para que haja a transição deste modelo convencional de agricultura, para um estilo de agricultura alicerçada nos princípios da Agroecologia.

Entende-se, portanto, que a inserção da agroecologia enquanto componente curricular pode ser um dos aspectos a contribuir para a redução dessa lacuna no processo de formação do agrônomo, de acordo com a percepção dos alunos amostrados nessa pesquisa.

\section{REFERÊNCIAS BIBLIOGRÁFICAS}

BONILLA, J. A. Agricultura ecológica, ciência e ética. In MICKLÓS, A. A. de W. (Coord.).Agricultura biodinâmica, a dissolução entre o homem e a natureza: reflexos no desenvolvimento humano. São Paulo: Antroposófica, 2001, p. 160 a 172. In:CAPORAL, F.R.; COSTABEBER, J. A.4Conferência Brasileira de Agricultura Biodinâmica, São Paulo. Agroecologia: alguns conceitos e princípios. Brasília: MDA/SAF/DATER-IICA. 2004.

BRASIL. Lei de Diretrizes e Bases da Educação Nacional (LDB): Lei n ${ }^{\circ}$ 9.394, de 1996. Brasília: Subsecretaria de Edições técnicas, 1997.

BRASIL. Ministério da Educação.Instituto Federal de Educação, Ciência e Tecnologia do Mato Grosso Campus: Campo Novo do Parecis. Plano de Curso de Agronomia. Outubro de 2008.

CAMPOS, A. G. Análise da formação de alunos do curso de agronomia do IFMT - Campus Campo Novo do Parecis: Um estudo de caso sobre a interface com a agroecologia. 2013. 55p. (Dissertação de Mestrado) UFRRJ, Rio de Janeiro, 2013.

CAPORAL, F. R.; COSTABEBER J. A; PAULUS, G. Agroecologia: matriz disciplinar ou novo paradigma para o desenvolvimento rural sustentável. Brasília (DF), Abril de 2006.

CAVAllET, V. J. . A Formação do Engenheiro Agrônomo em Questão. Educação Agrícola Superior, Brasília, v. 17, n.01, p. 9-17, 1999.

FLICK , U. Introdução à pesquisa qualitativa. 3 ed. Porto Alegre: Artemed, 2009.

GIL, A. C. Como Elaborar projetos de pesquisa. 5 ed. São Paulo: Atlas, 2010.

GLIESSEMAN, S. R. Agroecologia: processos ecológicos em agricultura sustentável. 4. ed. Porto Alegre: Editora da Universidade/UFRGS, 2009. 658p.

JESUS, E. L. Perfil do profissional para atuar em Agroecologia: um novo desafio às escolas de ciências agrárias. In: Federação dos estudantes de agronomia do Brasil. Formação profissional do agrônomo. Cruz das Almas: FEAB/CONFEA, 1996.

MAIA, V. M; ALEXANDRE, R. S.; SILVA, R. G. Desafios à formação do profissional em ciências agrárias. Revista Educação Agrícola Superior. Publicação da Associação Brasileira de Educação Agrícola Superior. ABEAS,v. 21, n. 01, 2006.

MARCONI, M. A.; LAKATOS, E. M. Fundamentos de metodologia científica. 7 ed. São Paulo: Atlas, 2010.

MORIN, E. A Cabeça bem-feita: repensar a reforma, reformar o pensamento. 8 ed. Rio de Janeiro: Bertrand Brasil, 2003. 128p.

OLIVEIRA, M. M. de. Como Fazer projetos, monografias, dissertações e teses. 5 ed. Rio de Janeiro: Elsevier, 2011.

SARANDÓN, S. J. Incorporando el enfoque agroecológico en las Instituciones de Educación Agrícola Superior: la formación de profesionales para una agricultura sustentable. RevistaAgroecologia e Desenvolvimento Rural Sustentável, v. 3, n. 2, p. 40-49, 2002.

SILVA, M. R. A agroecologia na formação do Técnico em Agropecuária do Colégio Agrícola Nilo Peçanha CANP/UFF no atual contexto do mercado de trabalho. In: Seminaria Internacional - Formación de Formadores para elDesarrollo Rural, 2008, Montevidéu. Educaçao, 2008.

SILVEIRA FILHO, J.; SALES, F. J. M. de; HAGUETTE, A. A Sustentabilidade da agricultura e o projeto formativo no curso de agronomia da Universidade Federal do Ceará. Revista Extensão Rural, v. 18, n. 21, p. 37-76, 2011.

SOARES, A. M. D.; BRAGA, A. M. Formação Profissional e Demandas Sociais. Revista Educação Agrícola Superior, Brasília: ABEAS, Edição Especial, 1997.

SOUZA, S. E. R. A Inserção de Educação Ambiental no Currículo do Curso de Agronomia: um estudo de caso na UFSM. Revista Educação Agrícola Superior, v. 21, p. 07-15, 2006.

YIN, R. K. Estudo de caso: planejamento e métodos. 4. ed. Porto Alegre: Bookman, 2010. 